\title{
PROPOSED E-LEARNING FRAMEWORK FOR SPECIAL NEED STUDENTS IN HIGHER EDUCATION INSTITUTIONS
}

\author{
Nethra Vaidhyanathan ${ }^{1}$, Toka Ahmed Awad Haroun², Vikas Rao Naidu*, \\ Raza Hasan ${ }^{4}$, Lilibeth Reales ${ }^{5}$, Karan Jesrani ${ }^{6}$ \\ ${ }^{1}$ Ms., Middle East College, OMAN,17f17419@mec.edu.om \\ ${ }^{2}$ Ms., Middle East College, OMAN, 17F17250@mec.edu.om \\ ${ }^{3}$ Dr., Middle East College, OMAN, vikasrn@gmail.com \\ ${ }^{4}$ Mr., Middle East College, OMAN, raza@mec.edu.om \\ ${ }^{5}$ Ms., Middle East College, OMAN, lilibeth@mec.edu.om \\ ${ }^{6}$ Mr., Middle East College, OMAN, kjesrani@mec.edu.om \\ ${ }^{*}$ Corresponding Author
}

\begin{abstract}
Education is a weapon to improve one's life. It helps to develop one's character and attitudes. The education of children is very important. It gives them a platform to develop their mind and body in terms of their abilities. Due to the impact of education on a child's development, these children are given equal opportunities to succeed in life. Special needs children deserve equal opportunity to get an education. This study aims to introduce an online framework for specially abled children during the outbreak of COVID-19. The research will come up with a well-defined framework in the field of education for specially abled children. Where the learning will be interactive. There have been various experiments in interactive learning for special needs children such as tap to talk, touch to speak. The research will give a framework that is specially designed and is interactive for special needs children. The research will formulate a well-defined framework for special needs children's education. It will be an interactive learning environment. The framework should also be designed in such a way that it fits the needs of the faculty members and the students.
\end{abstract}

Keywords: E-Learning, Special education in COVID-19, Education technology, Special need education.

\section{INTRODUCTION}

During the global pandemic Covid-19, all the offline classes have been converted into an online mode of education. The author's country and the rest of the world is facing lockdown by staying at home. There is a drastic increase in the spread of COVID-19. Few sectors of the country are adverse which are education, economy, employment etc.

Technology is playing a dominant role in the online mode of education. The world can be studying with one click on their respective devices. Technology helps teachers to communicate with their students and take classes. Computer science and information system are the two fields that give up new technology in action for the use of the common people. The author finds out that Augmented reality is been used in the education sector.

According to the author, the tools used in this mode of education are Email, Whatsapp, Facebook, MS Teams, Zoom, Youtube channel, screen recording application and PowerPoint presentation. These tools make life easier for the teacher as well as the student. The online examination can also be conducted using 
this application. The scheduled time for teaching in the author's country is from 8:00 am to 6:00 pm. The classes can be scheduled during this period. With the use of free and open source software, educational institutions can now adapt e-learning simply by improving their knowledge rather than investing much in hardware and infrastructure upgrades.(Vikas Rao Naidu, Singh, Al Harrasi, et al., 2017)(Sharma \& Naidu, 2020) The use of learning analytics to track students' participation in class activities has led to a closer look at their participation. Through a well-structured dashboard, the student's progress may be tracked. (Rao Naidu et al., 2017)

Every method has advantages and disadvantages. The users of this mode of education who are teachers and students face some issues. The author has stated few common problems faced by the users which are: the users may not have high speed internet to access the online education, the background might be noisy, the fluctuation of electricity, the fluctuation of the signal as everyone is using the internet, the members in the house may bother while attending or taking the online mode education. These e-learning systems must be implemented on the cloud for students to have global access at any time. Other significant benefits of cloud hosting include automated and scheduled material backups, instructor access to learning metrics, and so forth. (Vikas Rao Naidu et al., 2019) Technology is at its peak for changing its dynamics now and then. The author states that there is no technical support for special needs children. This field of education needs technological support as education is common for normal and special need children and also special need education are at an increasing rate year by year.

\section{LITERATURE REVIEW}

Learning is a continuous process of life, the highest level of human attitude, and the vision of the universe (Venna, 2013). In today's world, it is noticeable that a drastic change in various fields due to the recent technological advancement is happening especially in the field of education. One of the main trends in modern education nowadays is the gradual shifting of teacher-centered approach to student-centered approach to allow the student in discovering and constructing their knowledge (Ozunboylu, \& Ozcan, 2019). However, individuals with special needs require special teaching-learning methodologies as they have different requirements and characteristics from their peers in terms of psychological, social, mental, and emotional development (Baglama, Serttas and Demirok, 2017; Bateman and Bateman, 2014).

Teaching students with special learning disabilities (SLD) is a challenging task for teachers as the number of SLD is increasing. However, a various trend in teaching and learning methodologies used in special education which includes but not limited to collaborative working approach among teachers, setting high learning goals, different teaching strategies, and providing basic modifications motivates the SLD to be more engaged in the class. A Collaborative working approach is effective in teaching SLD as the conventional teacher in the classroom provides the module content while the special education teacher provides a piece of modified information based on the outline of the Individualized Education Program (IEP) depending on child disability. While setting a high learning goal can improve the SLD's motivation and achievements by setting a higher goal in some of the modules such as science and mathematics. The goal will study the strategy to improve the test grades or editing the laboratory reports to study the content and focusing on the goal will help SLD to progress towards the goal that makes them feel in control in their learning (DeBacker \& Nelson, 2000). The use of different teaching strategies in teaching SLD such as inquiry-based learning and cooperative learning that involves problem solving and critical thinking skills to conclude as this strategy focused on student-centered learning approach. Thus, this method helps the SLD to improve their skills in observing, measuring, classifying, interfering, hypothesizing, engaging in a controlled investigation, predicting, explaining and communicating which is a bit challenging for them (Wild \& Trundle, 2010). A cooperative learning teaching strategy is also an approach that involves the students in small groups and allowing to work together. The grouping is not based on their disability; instead, they come in all levels and each student is expected to complete the assigned task. In this manner, the student maximizes their ability while learning from the other students as well. Research supports this type of teaching strategy as this is proven to become very effective in improving cognitive skills, enhancing critical thinking, providing feedback, social and emotional development, promoting diversity, and reducing student attrition (Macgregor, Cooper, Smith, \& Robinson, 2000). Lastly, is the modification approach, the typical teacher must collaborate with the special needs teacher so this could be more effective. Some of the effective modifications techniques for SLD include the use of class time, textbook reading, mnemonics, homework assignments, and assessments (Morocco, Clay, Parker, \& Zigmond, 2006). The use of proper methodology is more important that than increasing the student's learning (Kurt and Yavuz, 2018) since teaching methods in special education aims to improve the behavior and decrease if not eliminate inappropriate behaviors for them to become more independent. Through various teaching methodologies are available nowadays to effectively teach the SLD, it is also necessary to consider and investigate the condition of the SLD's before choosing the most appropriate teaching methodology and preparing the program. 
Apart from the above-mentioned teaching methodologies, errorless teaching is one of the most broadly used teaching and learning methodologies in special education as this approach developed based on the skills and concept teaching is achieved with a positive effect of responses instead of errors during instruction (Wolery et al, 1988). Teaching based on errorless teaching methods, prompts are given for the child to display target behaviors and these prompts need to be provided based on a systematic plan to be effective.

Today, all individuals with special needs have the right to receive as their peers which has been supported by Fulcher (2015) as he mentioned that a need for legal, administrative and educational arrangements shall be implemented for special needs to get the same benefits from equal education and life opportunities as those with the normal developmental characteristics. Furthermore, Demirdag (2014) in his international journal titled "Effective teaching strategies and Student Engagement: Students with Learning Disabilities, he mentioned that individuals with disabilities (IDEA) and the No Child Left Behind (NCLB) are federal laws in the United States which states an equal right to those who doesn't have any disability. The law also states that it is the school responsibility to provide an Individualized Education Program (IEP) which includes instructional accommodations, modifications, and effective evaluation to ensure that students with special needs shall receive special education services within the general education classroom. SLD shall be included in the regular class environment to allow them to spend time with their peers and learn from them as well.

\section{METHODOLOGY}

The study conducted is exploratory. The quantitative method is used for the study. For the study, one Higher Education Institution (HEI) within the Sultanate of Oman was chosen and a questionnaire was filled by the students enrolled in the HEI.

\subsection{Research Model and Hypotheses}

For this purpose, extensive meetings were conducted with the faculty members at the HEI in Oman. This helped us identify the course of our research and modelling the research hypotheses.

H1: Interactive E-Learning framework for Special Need Students in Higher Education will have a positive and significant effect on their learning.

\subsection{Questionnaire Design}

A questionnaire is developed and used for data collection. A quantitative method is used with a survey technique. We designed a questionnaire having 10 questions, 8 containing a psychometric scale and 2 open ended question. The questionnaire psychometric scale comprises 5 questions or statements. A five-point rating scale was used for the questionnaire. The rest of the 3 questions requires age and yes/no responses.

Q1: Age?

Q2: Do you think special needs children should have a different way of teaching?

Q3: Special need children should be treated equally?

Q4: Advancement in special need education can help children learnt faster?

Q5: The teaching method used for normal children and special needs children have to be different?

Q6: Usage of technology can improve the quality of teaching and hence helps the faculty?

Q7: Parents should be aware of the children's teaching method?

Q8: Have you come across any applications which are used for special needs children?

Q9: If your answer to the above question is yes, then kindly name the application?

Q10: Any suggestions according to you?

\subsection{Reliability}

The reliability of a questionnaire can be considered as the consistency of the survey results. Items generated from the exploratory research with regards to the dependent variable were tested through Cronbach's alpha to determine the degree to which they captured the dependent variable. A high value of Cronbach's alpha does not imply that the measure is unidirectional or multidimensional. Covariance analysis is also conducted to check the dimensionality. 


\subsection{Validity}

Correlation analysis has been performed to yield conclusions invalidation studies. The validity of the questionnaire is determined by analyzing whether the questionnaire measures what it is intended to be measured. Correlation analysis was conducted from Q1 to Q8.

\subsection{Data Collection}

Ethical approval is necessary for data collection purposes. In this study, consent was obtained from the people involved by explaining to them the purpose of the study and its description. It was also communicated, and the study is of "no potential risk" and in case of any discomfort they can withdraw their participation at any given moment as it is voluntary participation. Privacy and confidentiality have been taken with the utmost priority. The data and information collected in this study were anonymously taken, no identification information has been discussed when reporting the data. The data is not stored and will be destroyed once the analysis has been performed. The data was collected from Fall 2020 to Spring 2021 and 80 observations were used for the study.

\subsubsection{Data Cleansing}

Data cleansing is performed to eliminate unnecessary data and separate data which is relevant for analysis in the study from Q1-Q8. Missing values were given 3 as neutral. Yes, the value was converted to 1 and No was converted to 0 .

\subsubsection{Data Partitioning}

The psychometric Scale was mapped with numerical values such that it can be useful for statistical analysis. Strongly Disagree was denoted by 1, Disagree denoted by 2, Neutral denoted by 3, Agree denoted by 4 and Strongly Agree was denoted by 5.

\section{RESULTS}

The researchers put through 8 variables with regards to the hypotheses. Table I presents the descriptive statistics of the research variables in terms of the distribution of frequencies.

\begin{tabular}{|c|c|c|c|}
\hline Question & Options & $\mathrm{N}$ & $\%$ \\
\hline \multirow{5}{*}{ Q1 } & Below 18 & 10 & 12.5 \\
\hline & $18-25$ & 43 & 53.75 \\
\hline & $26-40$ & 16 & 20 \\
\hline & $41-60$ & 9 & 11.25 \\
\hline & Above 60 & 2 & 2.5 \\
\hline \multirow{2}{*}{ Q2 } & Yes & 64 & 80 \\
\hline & No & 16 & 20 \\
\hline \multirow{5}{*}{ Q3 } & Strongly Agree & 47 & 58.75 \\
\hline & Agree & 19 & 23.75 \\
\hline & Neutral & 10 & 12.5 \\
\hline & Disagree & 2 & 2.5 \\
\hline & Strongly Disagree & 2 & 2.5 \\
\hline \multirow{3}{*}{ Q4 } & Strongly Agree & 49 & 61.25 \\
\hline & Agree & 17 & 21.25 \\
\hline & Neutral & 8 & 10 \\
\hline
\end{tabular}




\begin{tabular}{|c|c|c|c|}
\hline & Disagree & 4 & 5 \\
\hline & Strongly Disagree & 2 & 2.5 \\
\hline \multirow{5}{*}{ Q5 } & Strongly Agree & 43 & 53.75 \\
\hline & Agree & 16 & 20 \\
\hline & Neutral & 17 & 21.25 \\
\hline & Disagree & 2 & 2.5 \\
\hline & Strongly Disagree & 2 & 2.5 \\
\hline \multirow{5}{*}{ Q6 } & Strongly Agree & 42 & 52.5 \\
\hline & Agree & 22 & 27.5 \\
\hline & Neutral & 12 & 15 \\
\hline & Disagree & 3 & 3.75 \\
\hline & Strongly Disagree & 1 & 1.25 \\
\hline \multirow{5}{*}{ Q7 } & Strongly Agree & 48 & 60 \\
\hline & Agree & 19 & 23.75 \\
\hline & Neutral & 9 & 11.25 \\
\hline & Disagree & 2 & 2.5 \\
\hline & Strongly Disagree & 2 & 2.5 \\
\hline \multirow{2}{*}{ Q8 } & Yes & 13 & 16.25 \\
\hline & No & 67 & 83.75 \\
\hline
\end{tabular}

Table. 1: Distribution of Frequencies

\begin{tabular}{|c|c|c|c|c|c|}
\hline Question \# & Mean & Standard Error & Median & Mode & Standard Deviation \\
\hline 1 & 1.375 & 0.1043 & 1 & 1 & 0.9329 \\
\hline 2 & 0.8 & 0.0450 & 1 & 1 & 0.4025 \\
\hline 3 & 4.3375 & 0.1081 & 5 & 5 & 0.9671 \\
\hline 4 & 4.3375 & 0.1138 & 5 & 5 & 1.0181 \\
\hline 5 & 4.225 & 0.1139 & 5 & 5 & 1.0185 \\
\hline 6 & 4.2375 & 0.1129 & 5 & 5 & 1.0094 \\
\hline 7 & 4.3625 & 0.1071 & 5 & 5 & 0.9579 \\
\hline 8 & 0.1519 & 0.0406 & 0 & 0 & 0.3612 \\
\hline
\end{tabular}

Table. 2: Descriptive Statistics

Table 2 presents the descriptive statistics of the research variables in terms of mean, standard error, median, mode and standard deviation. 
IJAEDU- International E-Journal of Advances in Education, Vol. VII, Issue 20, August, 2021

Table 3 presents the reliability, ANOVA: Two-Factor without Replication is done that can be helpful to calculate Cronbach's alpha.

\begin{tabular}{|c|c|c|c|c|c|c|}
\hline Source of Variation & SS & df & MS & F & P-value & F crit \\
\hline Rows & 151.86 & 78.00 & 1.95 & 3.51 & 0.00 & 1.31 \\
\hline Columns & 1661.58 & 6.00 & 276.93 & 499.86 & 0.00 & 2.12 \\
\hline Error & 259.28 & 468.00 & 0.55 & & & \\
\hline Total & 2072.72 & 552.00 & & & & \\
\hline
\end{tabular}

Table 3: ANOVA: Two-Factor Without Replication

Cronbach's alpha is calculated by the formula below:

$$
\propto=1-(\operatorname{Error}(M S) / \operatorname{Rows}(M S))
$$

Using the equation (1) Cronbach's alpha value came out to be $\alpha=072$. Table IV presents the covariance to check the directionality among the variables.

\begin{tabular}{|c|c|c|c|c|c|c|c|c|}
\hline Question \# & Q1 & Q2 & Q3 & Q4 & Q5 & Q6 & Q7 & Q8 \\
\hline Q1 & 0.86 & & & & & & & \\
\hline Q2 & -0.16 & 0.16 & & & & & & \\
\hline Q3 & -0.13 & 0.07 & 0.92 & & & & & \\
\hline Q4 & -0.21 & 0.07 & 0.42 & 1.02 & & & & \\
\hline Q5 & -0.20 & 0.10 & 0.14 & 0.41 & 1.02 & & & \\
\hline Q6 & -0.13 & 0.08 & 0.28 & 0.48 & 0.30 & 1.01 & & \\
\hline Q7 & -0.25 & 0.11 & 0.30 & 0.52 & 0.49 & 0.36 & 0.91 & \\
\hline Q8 & 0.03 & 0.03 & -0.03 & -0.06 & 0.02 & 0.05 & 0.00 & 0.13 \\
\hline
\end{tabular}

Table 4: Covariance Analysis

Table 5 presents the correlation to check the validity among the variables.

\begin{tabular}{|c|c|c|c|c|c|c|c|c|}
\hline Question \# & Q1 & Q2 & Q3 & Q4 & Q5 & Q6 & Q7 & Q8 \\
\hline Q1 & 1 & & & & & & & \\
\hline Q2 & -0.44 & 1 & & & & & & \\
\hline Q3 & -0.14 & 0.18 & 1 & & & & & \\
\hline Q4 & -0.23 & 0.17 & 0.44 & 1 & & & & \\
\hline Q5 & -0.21 & 0.23 & 0.14 & 0.40 & 1 & & & \\
\hline Q6 & -0.14 & 0.21 & 0.29 & 0.48 & 0.29 & 1 & & \\
\hline Q7 & -0.28 & 0.29 & 0.33 & 0.53 & 0.51 & 0.38 & 1 & \\
\hline Q8 & 0.09 & 0.21 & -0.07 & -0.17 & 0.04 & 0.14 & -0.01 & 1 \\
\hline
\end{tabular}

Table 5: Correlation Analysis 
Table 6 presents the model summary of Linear Regression.

\begin{tabular}{|c|c|}
\hline \multicolumn{2}{|c|}{ Regression Statistics } \\
\hline Multiple R & 0.690343 \\
\hline R Square & 0.476573 \\
\hline Adjusted R Square & 0.424968 \\
\hline Standard Error & 0.774864 \\
\hline Observations & 80 \\
\hline
\end{tabular}

Predictors: (Constant), Q1, Q2, Q3, Q5, Q6, Q7 and Q8

Table 6: Model Summary

Table 7 presents the analysis of variance.

\begin{tabular}{|c|c|c|c|c|c|}
\hline Model & df & SS & MS & F & Significance F \\
\hline Regression & 7 & 38.8 & 5.54 & 9.23 & $0.00^{\mathrm{b}}$ \\
\hline Residual & 71 & 42.6 & 0.60 & & \\
\hline Total & 78 & 81.44 & & & \\
\hline
\end{tabular}

Predictors: (Constant), Q1, Q2, Q3, Q5, Q6, Q7 and Q8. b Dependent Variable:Q4

Table 7: ANOVA

Table 8 presents the equation variables.

\begin{tabular}{|c|c|c|r|r|r|r|r|r|}
\hline Model & Intercept & Q1 & Q2 & Q3 & \multicolumn{1}{c|}{ Q5 } & Q6 & Q7 & Q8 \\
\hline Coefficients & 0.376 & -0.046 & 0.295 & 0.238 & -0.061 & 0.157 & 0.278 & -0.554 \\
\hline Standard Error & 0.635 & 0.108 & 0.098 & 0.099 & 0.258 & 0.101 & 0.116 & 0.259 \\
\hline t Stat & 0.592 & -0.428 & 3.013 & 2.413 & -0.237 & 1.553 & 2.388 & -2.135 \\
\hline P-value & 0.556 & 0.670 & 0.004 & 0.018 & 0.814 & 0.125 & 0.020 & 0.036 \\
\hline Lower 95\% & -0.890 & -0.262 & 0.100 & 0.041 & -0.576 & -0.045 & 0.046 & -1.070 \\
\hline Upper 95\% & 1.642 & 0.169 & 0.490 & 0.435 & 0.454 & 0.359 & 0.510 & -0.037 \\
\hline
\end{tabular}

Table 8: Equation Variables

\section{DISCUSSION}

The analysis is based on 80 observations as shown in Table I, the responses recorded by the majority of the respondents represents the age group of $18-25$ years $(53.75 \%) .80 \%$ of respondents think that special needs children should have a different way of teaching. $58.75 \%$ strongly agrees on special needs children should be treated equally. $61.25 \%$ of respondents strongly agree that advancement in special needs education can help children learnt faster and effectively. $53.75 \%$ of respondents strongly agree that the teaching method used for children and special needs children has to be different depending on their requirements. $52.5 \%$ of respondents strongly agree on the usage of technology. Hence, can improve the quality of teaching and helps the faculty in their teaching styles. $60 \%$ of respondents strongly agree that parents should be aware of the children's teaching method use to disseminate the knowledge. $83.75 \%$ of respondents disagree on the availability of existing applications which are used for special needs children. Though through open ended questions researchers were able to gather suggestions from the respondents.

Also, to verify the frequency distribution, further statistical analysis using mean, median and mode were calculated as shown in Table II. Mean for Q1, Q2, Q3, Q4, Q5, Q6, Q7 and Q8 are 1.375, 0.8, 4.3375, $4.3375,4.225,4.2375,4.3625$ and 0.1519 respectively. The result shows that the respondents strongly agree with the Q3-Q7 questions asked in the questionnaire given the median and mode as 5 . Standard deviation for Q1, Q2, Q3, Q4, Q5, Q6, Q7 and Q8 are 0.9329, 0.4025, 0.9671, 1.0181, 1.0185, 1.0094, 0.9579 and 0.3612 respectively. Standard deviation indicates that the data points tend to be spread out to the mean.

Furthermore, ANOVA: Two-Factor without Replication is done to calculate Cronbach's alpha as shown in Table III and equation (1). Cronbach's alpha is used to measure the internal consistency on how closely related a set of items are as a group. The alpha coefficient for the four items was $\alpha=0.72$ suggesting that the items have relatively high internal consistency as the value of $\alpha>0.70$. Additionally, we investigated the dimensionality of scale using covariance analysis as shown in Table IV. The covariance suggests that the 
items or variables are unidirectional. Q1 covariance is 0.594 and corresponding items is having less covariance. Similarly, it can be looked for other Q1, Q3, Q4, Q5, Q6 and Q7 shows less covariance than Q2 and Q8.

Moreover, correlation analysis is done to evaluate the strength of the relationship between two or more quantitative variables as shown in Table V. For those who responded in the survey, Q1 was negatively correlated with all the questions making it non-significant. Similarly, Q2 was not having any correlation among the questions. Q3-Q7 correlated with higher importance with each other. This is evident that special needs student needs to be treated equally, new methods of teaching using technology can make them learn faster and improve in the quality of teaching. Parent's involvement in their learning can also help in the learning stages of the special needs student.

Besides, correlation analysis without running a test for significance, we are not able to infer the same correlation to the rest of the population from which our samples are drawn. For this purpose, linear regression analysis is done as shown in Table VI. Multiple $\mathrm{R}$ is the correlation coefficient that measures the strength of a linear relationship between two variables. 0.69 shows a strong positive relationship. $\mathrm{R}$ Square is the coefficient of determination, which is used as an indicator of the goodness of fit. It shows how many points fall on the regression line. $R$ Square 0.47 means that nearly half of the variance in the outcome variable is explained by the model. This is due to the predictors are trending linearly in terms of the response variable, which makes the $t$ values significant, but the $\mathrm{R}$ squared is low because the errors are large, which means that the variability in the data is large and thus the regression. Standard Error is another goodness-offit measure that shows the precision of the regression analysis, 0.77 suggests that the regression equation is precise due to the less standard error. Table VII represents an analysis of variance (ANOVA) Significance F is 0.0 which is less than 0.05 suggesting our linear regression model is good. This can also be verified by Table VIII P-value of Q1 (0.670), Q2 (0.004), Q3 (0.018), Q5 (0.814), Q6 (0.125), Q7 (0.020) and Q8 (0.036).

From the evidence provided above, we can conclude that hypothesis is verified and an Interactive ELearning framework for Special Need Students in Higher Education will have a positive and significant effect on their learning.

\section{PROPOSED FRAMEWORK AND CONCLUSION}

Keeping all the above aspects into consideration, the framework is proposed as shown in Fig. 1 for special needs education with interactive learning materials. Interactive content production necessitates careful content planning. Knowledge of Human Computer Interaction principles for e-learning content design, which establishes certain requirements for better engagement, is crucial in addition to planning. (Vikas Rao Naidu, Srinivas, et al., 2020) (Al Mahdi et al., 2019)

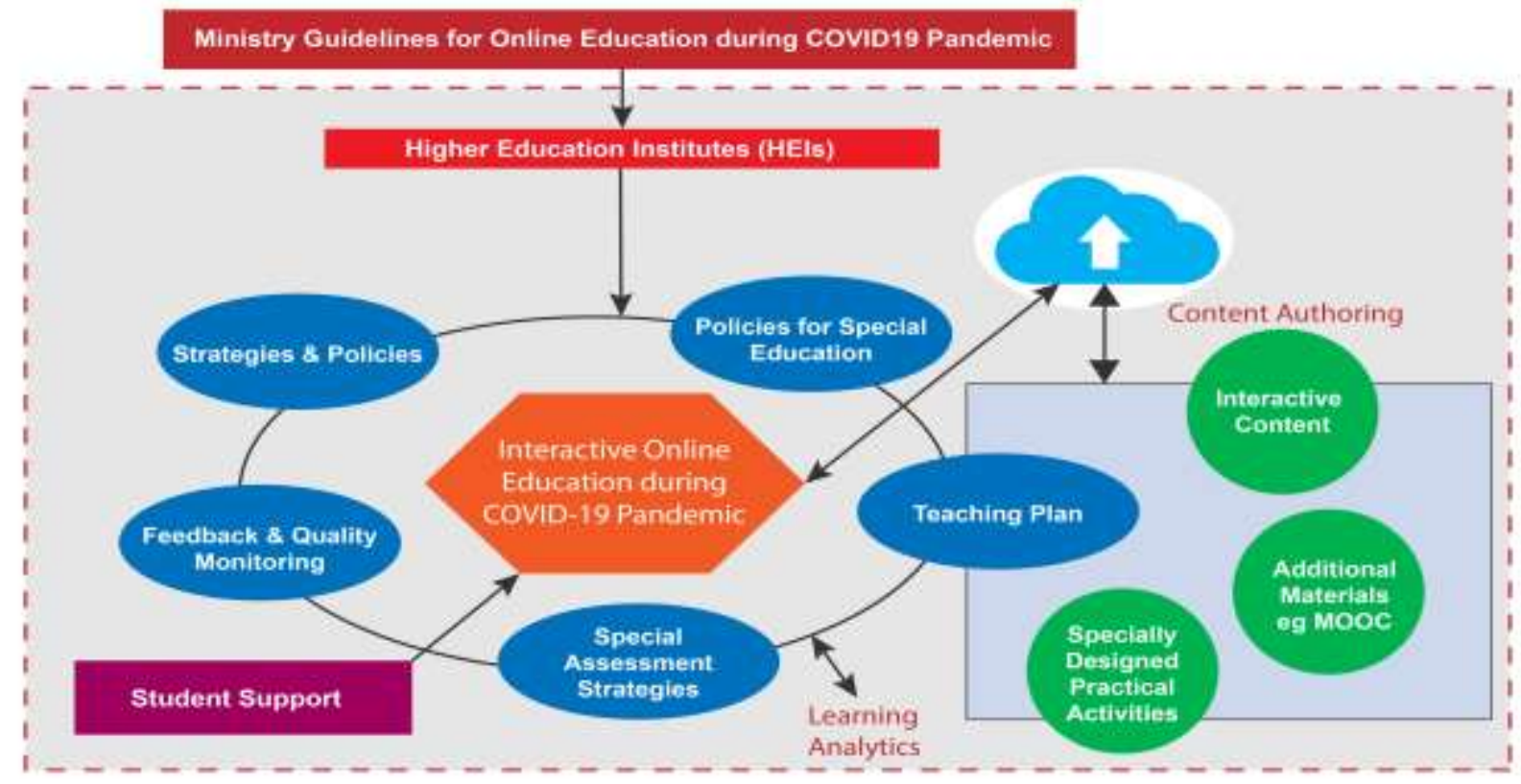

Fig. 1 Proposed framework of Special need education for HEls

Another key component is the game-based learning experience, which improves classroom engagement 
even more, especially during brainstorming and revision sessions. (Vikas Rao Naidu, Al Balushi, et al., 2017) Other emerging trends in education technology include the use of machine learning algorithms in conjunction with learning management systems to analyze student progress and make predictions from which further results can be drawn, the use of social media, particularly during online education in Pandemic, various data mining techniques for educational data, and emerging big data trends. (Agarwal et al., 2021)(Agarwal et al., 2019) (Al Mamari et al., 2019)(Hasan et al., 2020)(Poloju \& Naidu, 2020)(Mohammed et al., 2019)(Mohammed et al., 2020)(Vikas Rao Naidu, Singh, et al., 2020)

As seen from the proposed framework, the Ministry of Higher Education issues guidelines for teaching and learning processes to be taken during the Online mode, especially during situations like the current pandemic. HEls follows all the guidelines issued by the Ministry and prepare their Strategies and Policies for the module delivery and assessments. It is proposed to form different policies for the students with special needs (such as dyslexia, handicapped etc). Since these students are going to attend online classes, it becomes very difficult to handle the session using a routine way. Hence some special measures should be taken and followed. Special assessment strategies are to be formed here along with enough provision for student support in online mode. This includes online consultation, peer tutoring etc.

It is recommended to use cloud storage to enable global access to the learning materials. (V.R. Naidu et al., 2019)(Bhat et al., 2018) Sometimes due to the nature of learning material, which may contain audio, video, animation, images etc, the size of content may increase. So for that appropriate optimization should be done for multimedia based materials before uploading on a cloud.

Faculty members are advised to author their content along with interactivity, through which the student's involvement/interactions with the content could be traced. (Vikas Rao Naidu, Singh, Hasan, et al., 2017) For this learning, analytics should be embedded in the learning management system and the faculty members should be trained accordingly to monitor the progress of the students through a dashboard.

Feedback and Quality monitoring are the essential components during the entire process through which the entire process can be improved before moving to the next session (or semester).

\section{ACKNOWLEDGEMENT}

The authors would like to thank the management and staff of Middle East College, Oman for their encouragement in this research.

\section{REFERENCE LIST}

Baglama, B., Demirok, M., \& Serttas, S. (2017). Examining the relationship between pre-ser-vice teachers' perceptions on individual differences and attitudes towards individuals with special needs. Journal Of Educational Sciences \& Psychology, 7(2). Retrieved 27 May 2021, from http://jesp.upgploiesti.ro/index.php?option=com_phocadownload\&view=category\&id=27:journal-vol-vii-Ixix-no22017\&Itemid=16.

Bateman, D. F., \& Bateman, C. F. (2014). A principal's guide to special education. Council for Exceptional Children. https://files.eric.ed.gov/fulltext/ ED455624.pdf

DeBacker, T. K., \& Nelson, R. M. (2000). Motivation to learn science: Differences related to gender, class type, and ability. The Journal of Educational Research, 93(4), 245-254.

Demirdag, S. (2014). Effective Teaching Strategies and Student Engagement: Students with Learning Disabilities. International Journal of Teaching and Education, 2(3), 168-172.

Fulcher, G. (2015). Disabling policies? A comparative approach to education policy and disability. Routledge. https://doi.org/10.4324/9781315668253

Kurt, F., \& Yavuz, F. (2018). An adaptation of traditional Turkish educational games to the teaching of

vocabulary in EFL environment. International Journal of New Trends in Social Sciences, 2(2), $25-31$. https://doi.org/10.18844/ijntss.v2i2.3952

MacGregor, J. (Ed.). (2000). Strategies for energizing large classes: From small groups to learning communities: New directions for teaching and learning (No. 81). Jossey-Bass.

Morocco, C. C., Clay, K., Parker, C. E., \& Zigmond, N. (2006). Walter Cronkite high school: A culture of freedom and responsibility. Learning Disabilities Research \& Practice, 21(3), 146-158. 
Uzunboylu, H., \& Ozcan, D. (2019). Teaching methods used in special education: A content analysis study. Nter-National Journal of Cognitive Research In Science, Engineering And Education (IJCRSEE), 99-107.

Venna, R. (2013). Blog. Why learning is a continuous process of your life?. Retrieved 27 May 2021, from https://blogs.sap.com/2013/09/26/why-learning-is-a-continuous-process-of-your-life/.

Wild, T. A., \& Trundle, K. C. (2010). Conceptual understandings of seasonal change by middle school students with visual impairments. Journal of Visual Impairment \& Blindness, 104(2), 107-118.

Wolery, M., Bailey, D. B., \& Sugai, G. M. (1988). Effective teaching: Principles and procedures of applied behavior analysis with exceptional students (No. Sirsi) i9780205113088). http://www. sidalc.net/cgibin/wxis.exe/?/sisScript=SUV.xis \&method=post\&formato=2\&cantidad=1\&expresion=mfn=013732

Agarwal, A., Naidu, V. R., \& Al Mamari, R. (2019). a Framework To Enhance Learning Experience in Flipped Classroom Based on Student Accountability Towards Active Participation. EDULEARN19 Proceedings, 1(July), 1569-1577. https://doi.org/10.21125/edulearn.2019.0464

Agarwal, A., Saqib, M., Hasan, R., Srinivas, S., Rao Naidu, V., \& Jesrani, K. (2021). Educational Association Mining on the Use of Media Platforms for e-Learning. 2021 2nd International Conference on Computation, Automation and Knowledge Management (ICCAKM). https://doi.org/10.1109/ICCAKM50778.2021.9357727

Al Mahdi, Z., Rao Naidu, V., \& Kurian, P. (2019). Analyzing the Role of Human Computer Interaction Principles for E-Learning Solution Design (pp. 41-44). Springer, Cham. https://doi.org/10.1007/978-3030-01659-3 6

Al Mamari, R., Naidu, V. R., \& Agarwal, A. (2019). A PROPOSED FRAMEWORK FOR EFFECTIVE USAGE OF SOCIAL MEDIA IN HIGHER EDUCATION ESTABLISHMENTS. EDULEARN19 Proceedings, 1 , 7337-7341. https://doi.org/10.21125/edulearn.2019.1755

Bhat, A. Z., Naidu, V. R., \& Singh, B. (2018). Multimedia Cloud for Higher Education Establishments: A Reflection. In Advances in Intelligent Systems and Computing (Vol. 841). https://doi.org/10.1007/978981-13-2285-3 81

Hasan, R., Palaniappan, S., Mahmood, S., Naidu, V. R., Agarwal, A., Singh, B., Sarker, K. U., Abbas, A., \& Sattar, M. U. (2020). A Review: Emerging Trends of Big Data in Higher Educational Institutions (pp. 289-297). Springer, Singapore. https://doi.org/10.1007/978-981-15-2329-8_29

Mohammed, Q. A., Naidu, V. R., Hasan, R., Mustafa, M., \& Jesrani, K. A. (2019). DIGITAL EDUCATION USING FREE AND OPEN SOURCE TOOLS TO ENHANCE COLLABORATIVE LEARNING. IJAEDUInternational E-Journal of Advances in Education, 13, 50-57. https://doi.org/10.18768/ijaedu.531636

Mohammed, Q. A., Rao Naidu, V., Said, M., Al Harthi, A., Babiker, S., Al Balushi, Q., Yousuf, M., Rawahi, A., Harib, N., \& Al Riyami, S. (2020). ROLE OF ONLINE COLLABORATIVE PLATFORM IN HIGHER EDUCATION CONTEXT. In IJAEDU-International E-Journal of Advances in Education: Vol. VI (Issue 17). https://doi.org/10.18768/IJAEDU.789422

Naidu, V.R., Bhat, A. Z., \& Singh, B. (2019). Cloud Concept for Implementing Multimedia Based Learning in Higher Education. In Advances in Science, Technology and Innovation. https://doi.org/10.1007/978-3030-01659-3_11

Naidu, Vikas Rao, Al Balushi, H., \& Bhatia, S. (2017). Effectiveness of Free \& Open Source Tools To Enhance Game Based Learning Experience in School Education. EDULEARN17 Proceedings, 1(July), 6604-6609. https://doi.org/10.21125/edulearn.2017.2505

Naidu, Vikas Rao, Bhat, A. Z., \& Singh, B. (2019). Cloud Concept for Implementing Multimedia Based Learning in Higher Education (pp. 81-84). Springer, Cham. https://doi.org/10.1007/978-3-030-016593_11

Naidu, Vikas Rao, Singh, B., Al Harrasi, R. A., \& Al Balushi, H. H. (2017). TECHNOLOGY ENHANCED LEARNING ASSISTED BY FREE AND OPEN SOURCE SOFTWARE. IJAEDU- International E-Journal of Advances in Education. https://doi.org/10.18768/ijaedu.338515

Naidu, Vikas Rao, Singh, B., Farei, K. Al, \& Suqri, N. Al. (2020). Machine Learning for Flipped Teaching in Higher Education-A Reflection (pp. 129-132). Springer, Cham. https://doi.org/10.1007/978-3-03032902-0_16

Naidu, Vikas Rao, Singh, B., Hasan, R., \& Al Hadrami, G. (2017). Learning Analytics for Smart Classrooms 
in Higher Education. IJAEDU- International E-Journal of Advances in Education, July, 440-446. https://doi.org/10.18768/ijaedu.338514

Naidu, Vikas Rao, Srinivas, S., Al Raisi, M., \& Dattana, V. (2020). Evaluation of Hypermedia Tools in Terms of Usability Heuristics for English Language Teaching. Arab World English Journal (AWEJ), 133-149.

Poloju, K. K., \& Naidu, V. R. (2020). Impact of E-tools in Teaching and Learning for Undergraduate Students. In H. S. Saini, R. K. Singh, M. Tariq Beg, \& J. S. Sahambi (Eds.), Innovations in Electronics and Communication Engineering (pp. 783-790). Springer Singapore.

Rao Naidu, V., Singh, B., Hasan, R., \& Al Hadrami, G. (2017). LEARNING ANALYTICS FOR SMART CLASSROOMS IN HIGHER EDUCATION. In IJAEDU- International E-Journal of Advances in Education (Vol. 3). http://ijaedu.ocerintjournals.org

Sharma, A., \& Naidu, V. R. (2020). a Study on Emerging Trends To Enhance Learning Experience in Higher Education Institutions. INTED2020 Proceedings, 1(March), 7391-7396.

https://doi.org/10.21125/inted.2020.1974 